\title{
Role of Focus Group Discussion (FGD) in e-Business Research
}

\author{
Norshakirah Ab Aziz \\ Information System Department, Universiti Tenaga Nasional, Jalan IKRAM-UNITEN, Selangor, Malaysia \\ Email: norshakirah@uniten.edu.my
}

Received 11 January 2015; accepted 26 January 2015; published 29 January 2015

Copyright $(2015$ by author and OALib.

This work is licensed under the Creative Commons Attribution International License (CC BY).

http://creativecommons.org/licenses/by/4.0/

(C) (i) Open Access

\begin{abstract}
e-Business is a vast area of study. Normally Information System researchers preferred to use a combination of quantitative and qualitative study or known as Mixed Method approach. This is because qualitative study is able to explain the quantitative finding in more details. Malaysian e-Supply Chain (e-SC) was chosen as domain for this study and the ultimate goal of research is to identify measurement parameters for trusted trading partner. This study focused on the role of Focus Group Discussion (FGD) as a tool for e-Business research included with the FGD procedure, size of participant, and challenges in conducting the FGD sessions.
\end{abstract}

\section{Keywords}

Focus Group Discussion, FGD, e-Business, Mixed Method

Subject Areas: Applications of Communication Systems

\section{1. e-Business}

e-Business rapid expansion in Malaysia encourages people to do business online effectively and efficiently. Majority Malaysian big firms have their e-Business application such as e-Procurement, e-Bidding, and e-Tender which purposely to reduce time and cost [1]. Admittedly, Internet technology has changed the way people live by connecting people at anywhere, anytime and changed the way people manage their complexities such as chores, business and social networking [2]. This study conducted in Malaysian e-Supply Chain (e-SC) using Mixed Method approach which ultimate goal of the study was to identify measurement parameters for identification trusted trading partner. This paper focused on role of focus group in e-Business research. According Ayala and Elder [3], FGD considered useful method to gather evidences in qualitative method research especially for Grounded Theory (GT) study. This method is used particularly when an in-depth understanding of certain facts is needed; and this cannot be achieved using quantitative methods [3] [4]. It has been popular among many information system researchers due to ability to explain the results of quantitative findings in more 
details as well as derived theory/knowledge founded in data collection and analysis [4]-[6].

\section{Focus Group Discussion (FGD)}

FGD is related to qualitative research which used to provide researchers with data which are not obtainable through documentation or record [7]. FGD had been established since 1926 [8] that has been increasingly used in the social science researches since 1980s [9]. According to Mack et al. [10], FGD completely depends on participants to generate data. Savin-Baden and Major [11] further said that FGD can be defined as "a unique kind of interview, in that it collects data from a number of people in a manner that is non-quantitative".

However, the strength of the FGD method as compared to in-depth interviews are in the dynamic conversation, reaction response in a short time period and the group participants are from the identified experts that can give data or feedback that may not be found in any record or documentation [7] [12]-[15]. On the other hand, in-depth interview focuses on the individual experiences, opinions, feeling, perspectives on how they see particular events, phenomena and beliefs [10]. The purpose of conducting FGD in this study was to confirm the needs of trust values in the Malaysian e-SC, as well as to identify the measurable parameters which can be used to represent the four trust values identified. At the end the trust values identified (competence, identification, openness and reliability) will help to identify trusted partner for B2B collaboration.

\subsection{Number of Participants}

FGD is made up of people with certain commonality and heterogeneity characteristics and similar levels of understanding of a topic, rather than aiming for diversity [16]. As for the size of FGD participants, various numbers were reported. For example, Litosseliti [17] suggested that the group should consist of between six to ten participants, and [12] [18] believed that the group should have between six to eight members. On the other hand, [19] and [4] agreed that six to twelve should be a good number, while [15] believed it should be ten to twelve participants. FGD can be done at one shot or can be conducted in several mini groups. For mini groups, the number of participants can range from as few as three, four to six, four to as many as twelve, fourteen, depending on the research purposes [16]. Smaller groups are more appropriate if the aim is to explore complex, controversial, emotional topics, sensitive issue or to encourage details accounts [14]. Overall small groups show greater potential [18]. Small focus groups or mini focus groups with four to six participants are becoming increasingly popular because smaller group are easier to recruit and host and the setting is more comfortable for participants [15].

Actually, small group may be advantageous if the topic is a very complex and if we are dealing with experts. Focus groups of a small size, i.e., three, were successfully used by [12] in his study. As being advised by [15], more than ten participants are difficult to control, and they limit each person's opportunity to share insight and observations. However, for this study three groups have been identified to undergo FGD sessions with each group having four people as participants. Altogether there were twelve people involved in the FGD. This is acceptable since as mentioned by [14], and [18], FGD can be conducted in mini groups. Regarding the number of participants in a mini group, as cited in [12], it can go as few as three, depending on the research purposes and it has been successful. As for this study, mini group was selected to encourage participants to give detailed accounts of the topic to be discussed, which is trust in the Malaysian e-Supply Chain (e-SC). Besides the advantages mentioned above, the small group is also easier to control, recruit, host, and allows participants to contribute insight, experience and observation [15]. In fact, small group shows greater potential [18] because it is easy to handle, the communication is clearer, more focused and less misunderstanding between participants as well between participants and observers. In our work we use three different mini groups.

\subsection{FGD Procedure}

To ensure the process of collecting data smoothly run, there are a few procedure must be follow. Figure 1 shows the detail procedure to conducts mini FGDs which includes pre, post and the sessions themselves. Several procedures were carried out such as identifying the objectives and goals of the FGD, preparing the FGD questions, identifying the moderator to conduct the FGD as well as selecting the participants for the FGD. This followed by telephone calls and the sending of invitation letters to participants and also several follow ups which led to the agreement on the date, time and venue for the FGD session. There are few things need to consider before start 


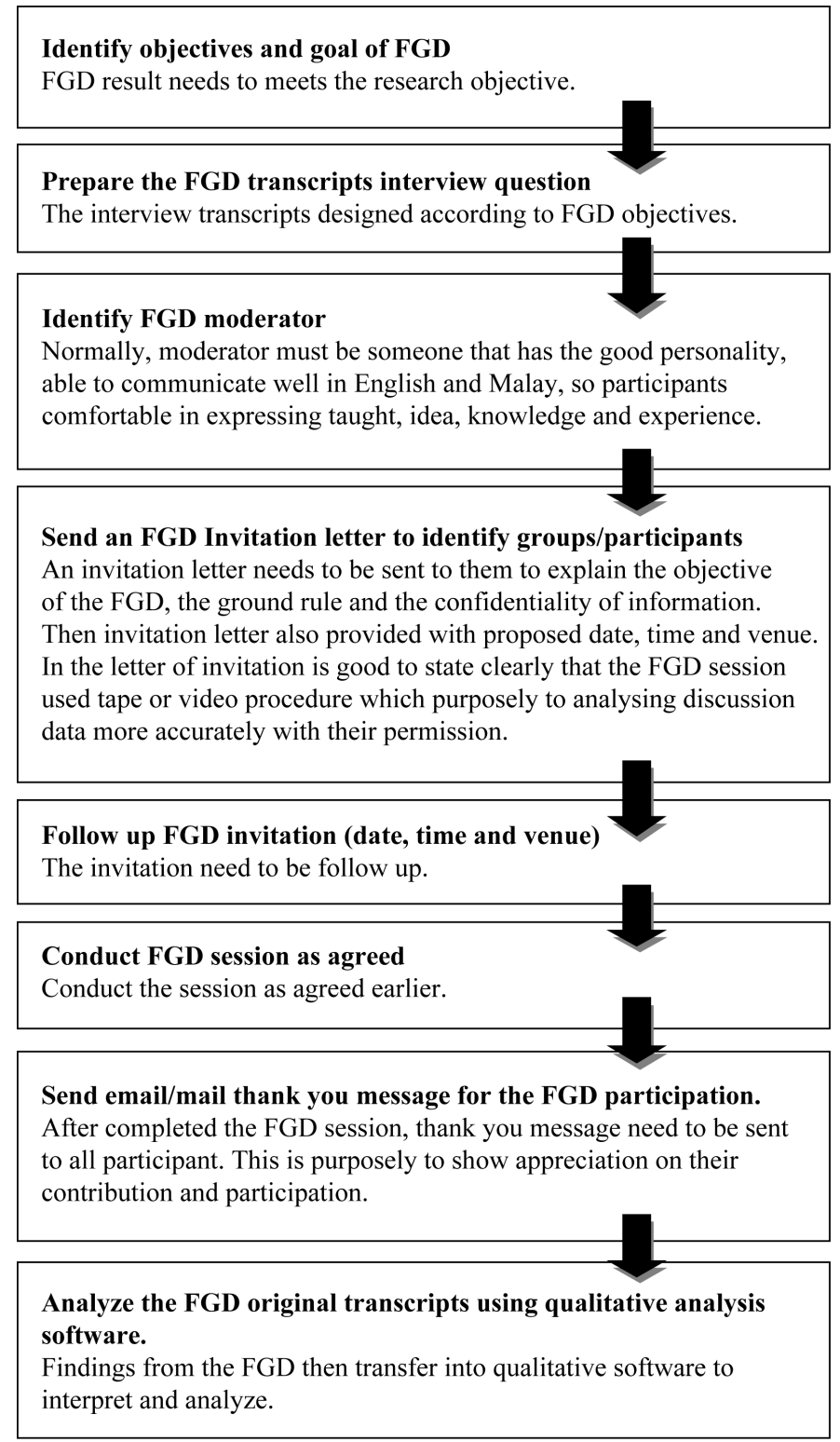

Figure 1. FGD preparation.

the FGD session. This included the process of participants' selection, moderator, and the confidentiality of information. Below are steps conducted in this study.

\subsection{FGD Participants Profiles}

For this study participants' profile, they were from senior executives, middle level positions and higher level managerial posts which can be considered as experts in their respective jobs. They were the people who have knowledge and experience with the issues that are being investigated. The experts also have the capacity and willingness to participate and have sufficient time for this study. At the same time, they must have effective communication skill to smoothen the FGD process. Three groups were chosen in this study, and they were the experts in the research and development, business collaboration and partnering; and experts in selling and buying deal of the business products. As previously mentioned, this study has 3 mini groups. First group is Research Institute for domain selected; second group is Malaysian Vendor Company; and the third group is one of the Malaysian Government-Linked Companies as shown in Figure 2. 

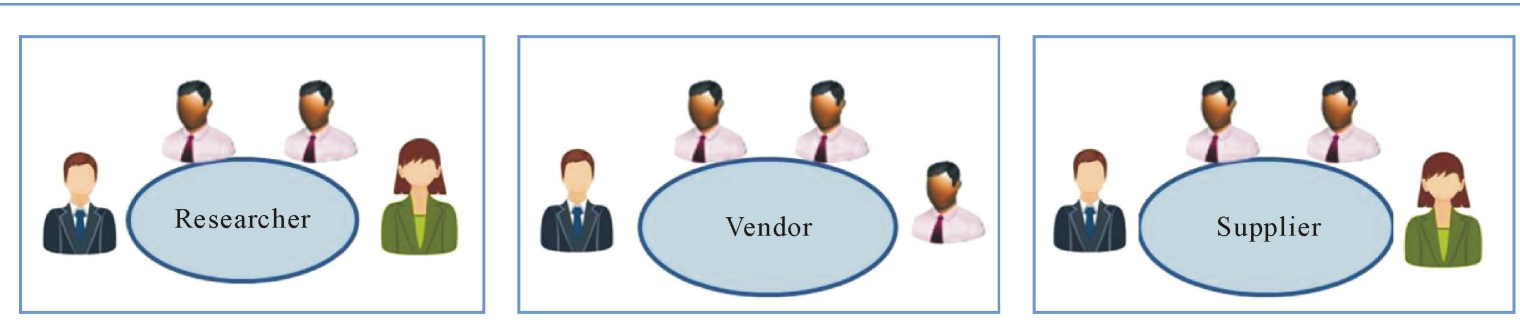

Figure 2. The FGD participants arranged in three different mini groups.

\subsubsection{First Group-Researcher}

The first group was composed of the researchers from the identified domain of study which a body provides updated and current information on issues regarding industry. In other words, they are researchers from the industry. Their opinion, idea, knowledge and feedback are needed in order to understand the current industry issues and update. They are the committed person in research and development for Malaysian industry. Any issues happened in the industry; they are the right person to refer. In this group, one of the participants is actually the director for the institute, which contributed much information that could not find in the documentation or record. He shares the experienced as a researcher, especially on how to identify trusted partners in the conventional way and how the industry grows. The group was asked about trust definition, trust values characteristics, trust values ranking and trust measurement parameter. They were informed about the result from quantitative survey and the sessions help explain the reason of the results in more details.

\subsubsection{Second Group-Vendor Company (Private Owned Company)}

The second group is Vendor Company. The inclusion of the group in the FGD was due to the belief that the respondents' knowledge can help to explain the trust value definition, characteristic and the measurement parameters for e-SC from their perspective as a vendor. They contributed much information on current issues happening in the industry and about how they try to survive in the industry. The company has experience in many tender projects and evaluates more than 20 companies by follows the Malaysian Government standard which based on highest score and the selection is manually without IT application system help. All the decision is made during the tender evaluation meeting. FGD session helps the company identify their own standard and explain finding in quantitative study result. For example, to evaluate competency of partner, it can be measure based on previous performance record, the total of successful project and the total years experienced in the industry. For reliability value, the commitment and consistency in behavior; and intellectual and physical capabilities of trading partner also considered important to ensure the project is completed on time and within the budget provided.

\subsubsection{Third Group—Government-Linked Companies (GLCs)}

The third group was from a Malaysian GLC's company. The company has started its operations in 1966 and owns four core businesses such as asset and facility management. Their knowledge on "how to select the right trading partner" and "how to collaborate in B2B" is useful for this study. Third group for the FGD session is from supplier group. The participants that involved in the FGD are from the procurement team which from the level of managerial post and senior's executive and has experience evaluates more than 100 companies. They also have experience in e-Procurement, e-Bidding and e-Tender. They are responsible in any decision regarding buying and selling construction product for all projects for the groups. They are also responsible in company vendor management. This group helps in explaining how they evaluate their business partner and share their knowledge in the trust measurement parameter. Their feedbacks are valuable for this study because this company is well known in Malaysia as the leading engineering conglomerate. This group helps explain on how to measure each of identified trust values. Most of the inputs are useful to explain the quantitative result.

\section{FGD Challenges}

Due to the difficulties in assembling the three groups at the same common place and time, the three FGDs were conducted at different dates, times and venues but following the same procedures. The duration of an FGD ses- 
sion of this study was only one hour per session. During the FGD session itself, the participants were asked to sit in a circle. They were each given a piece of paper containing the transcribed FGD questions. Then the moderator threw the first question and asked each of the participants for individual response. After that they were asked to discuss or debate the issue among themselves. In doing this, the participants were encouraged to share their ideas, opinion, knowledge, experience and observation. Actually, the interview transcripts were email to them three days before the session date. This purposely to give them view, what will be discussing during the session.

The same procedures were followed for the rest of the questions. In order to capture the activities and information transpired during the session, the session was recorded on tape, and the participants were also encouraged to write any valuable information on their transcripts, which were collected at the end of the session. In order to capture all valuable information, the tape record used in the session and only used one moderator responsible in one FGD session. After the session was successfully completed, a thank you email was sent to each of the participants. The information gathered from the session was then analyzed using qualitative analytical software called ATLAS.ti. The results of this qualitative study then merged with result from quantitative study in order to design e-SC trust model for Business to Business collaboration.

\section{FGD Analysis}

In the conventional way, FGD analysis is usually performed manually which the original transcript will be printed for analysis and if we deal with large amount of data, the manual way might be tedious and prone to errors. However, in this study, the data collected was composed and analysed using qualitative analytical software named ATLAS.ti. During the analysis process, important concepts will be highlighted and codes will be created according to the quotations found in the transcript.

Prior to the analysis step, first, the interview transcripts from all of the participants of an FGD session were compiled into one group transcript which is known as Hermeneutic Unit (HU). Thus, there were three HUs created to represent the three FGD sessions in this study. After that, the content of the HU can be analyzed sentence by sentence, statement by statement, paragraph by paragraph, story by story, or incident by incident in order to extract important ideas from the group. However, for this study the content was analyzed sentence by sentence.

According to Onwuegbuzie et al. [4], there are three types of coding to be done when analyzing the data for GT, which are open coding (category), axial coding (sub category) and selective coding (main category) analysis. Open coding is the process of generating initial concepts or categories from the original data/transcripts [4] [7]. In other words, open coding summarizes texts into codes to represent some phenomenon or events. The original transcript interpreted text into the codes or "category". Open coding is considered as the first step taken for the analysis. The quotations from the raw data was analyzed and coded into meaningful code that we can easily understand.

Axial coding is considered as the second process in analyzing sentence in FGD. Generally, axial coding is about the process of relating the similar categories linked to each other into "sub categories" [4]. The data gathered is analyzed to find consistencies and differences. The consistencies between codes in the files show similar idea on the topic discussed. For this study, the axial coding process reveals the characteristics for each of trust values, which consequently can be considered as the trust characteristics for the value identified. At the same time the "sub category" or axial coding analysis helps in identifying the metrics/parameters needed to measure the trust value. As the end or the last process of analyzing the sentence, selective coding integrates the category and sub categories into one theory [20]. The selective coding integrates the codes created into one network. This can helps to design the e-SC trust model for e-SCM integrator. After both phase in mixed method research completed, then the process of collate and merge the result started. The finding from both phases contributes to the design of the e-SC trust model.

\section{Conclusion}

FGD result strongly supports findings in the quantitative analysis consequences, and helps this study identify trust measurement parameters which used to calculate trust score potential trading partner. The e-SC trust model with detail trust measurement guideline, transformed into Web Based Expert System. This system can be used as guidelines for anyone to be integrator in industry and can be a good model to be extended to other industries or business with similar process. The most important thing is that FGD is a useful research tool for e-Business 
research which helps to explain each of quantitative findings more details. At the same time, FGD help to collect undocumented information, especially from human experience perspective. The popularity of FGD in academic research as research tool is undeniable as proven help this study to identify trust measurement parameters for e-SC trust model.

\section{References}

[1] Ab Aziz, N., Ahmad, R. and Dominic, P.D.D. (2014) Trust Model for e-Supply Chain Management (e-SCM) Business to Business (B2B) Collaboration. Australian Journal Basic \& Applied Science, 8, 450-454.

[2] Mukhtar, M., Jailani, N., Abdullah, S., Yahya, Y. and Abdullah, Z. (2009) A Framework for Analyzing e-Supply Chains. European Journal of Scientific Research, 25, 649-662.

[3] Ayala, G.X. and Elder, J.P. (2011) Qualitative Methods to Ensure Acceptability of Behavioral and Social Interventions to the Target Population. Journal of Public Health Dentistry, 71, S69-S79. http://dx.doi.org/10.1111/j.1752-7325.2011.00241.x

[4] Onwuegbuzie, A.J., Dicnkinsion, W.B., Leech, N.L. and Zoran, A.G. (2009) A Qualitative Framework for Collecting and Analyzing Data in Focus Group Research. International Journal of Qualitative Methods, 8, 21.

[5] Johnson, R.B. and Onwuegbuzie, A.J. (2004) Mixed Methods Research: A Research Paradigm Whose Time Has Come. Educational Researcher, 33, 14-26. http://dx.doi.org/10.3102/0013189X033007014

[6] Onwuegbuzie, A.J. and Leech, N.L. (2006) Linking Research Questions to Mixed Methods Data Analysis Procedures. The Qualitative Report, 11, 474-498.

[7] Byers, P.Y. and Wilcox, J.R. (1991) Focus Groups: A Qualitative Opportunity for Researchers. Journal of Business Communication, 28, 63-78. http://dx.doi.org/10.1177/002194369102800105

[8] McLafferty, I. (2004) Focus Group Interviews as a Data Collecting Strategy. Journal of Advance Nursing, 48, 187-194. http://dx.doi.org/10.1111/j.1365-2648.2004.03186.x

[9] Yee, L.H. and Seong, L.K. (2009) Buying via Internet. http://biz.thestar.com.my/news/story.asp?file=/2009/4/11/business/3620542

[10] Mack, N., Woodsong, C., MacQueen, K., Guest, G. and Namey, E. (2005) Qualitative Research Methods: A Data Collector's Field Guide. Family Health International (FHI), USA.

[11] Savin-Baden, M. and Major, C.H. (2010) New Approaches to Qualitative Research: Wisdom and Uncertainty. Routledge, London.

[12] Bloor, M., Frankland, M.J., Thomas, M. and Stewart, K. (2001) Focus Groups in Social Research. Sage Publications Ltd., London.

[13] Coenen, M., Stamm, T., Stucki, G. and Cieza, A. (2011) Individual Interviews and Focus Groups in Patients with Rheumatoid Arthritis: A Comparison of Two Qualitative Methods. Quality of Life Research, 21, 359-370.

[14] Jordan, J., Lynch, U., Moutray, M., O’Hagan, M.T., Orr, J., Peake, S. and Power, J. (2007) Using Focus Groups to Research Sensitive Issues: Insights from Group Interviews in Nursing in the Northern Ireland “Troubles”. International Journal of Qualitative Methods, 6, 1-19.

[15] Krueger, R.A. and Casey, M.A. (2000) Focus Groups: A Practical Guide for Applied Research. 3rd Edition, Sage Publications, Inc., Thousand Oaks.

[16] Aziz, N., Ahmad, R. and Dominic, D.D. (2011) Preliminary Study Collaboration Method through Trust Values for e-Supply Chain Integrator: A Case Study of Malaysian Construction Industry. National Postgraduate Conference, Kuala Lumpur, 19-20 September 2011, 1-5.

[17] Litosseliti, L. (2003) Using Focus Groups in Research. Continuum.

[18] Rabiee, F. (2004) Focus-Group Interview and Data Analysis. Proceedings of the Nutrition Society, 63, 655-660. http://dx.doi.org/10.1079/PNS2004399

[19] Suzuki, K., Morimoto, I., Mizukami, E., Otsuka, H. and Isahara, H. (2009) An Exploratory Study for Analyzing Interactional Processes of Group Discussion: The Case of a Focus Group Interview. AI \& Society, 23, 233-249.

[20] Bitsch, V. (2005) Qualitative Research: A Grounded Theory Example and Evaluation Criteria. Journal of Agribusiness, 23, 75-91. 
Scientific Research Publishing (SCIRP) is one of the largest Open Access journal publishers. It is currently publishing more than 200 open access, online, peer-reviewed journals covering a wide range of academic disciplines. SCIRP serves the worldwide academic communities and contributes to the progress and application of science with its publication.

Other selected journals from SCIRP are listed as below. Submit your manuscript to us via either submit@scirp.org or Online Submission Portal.
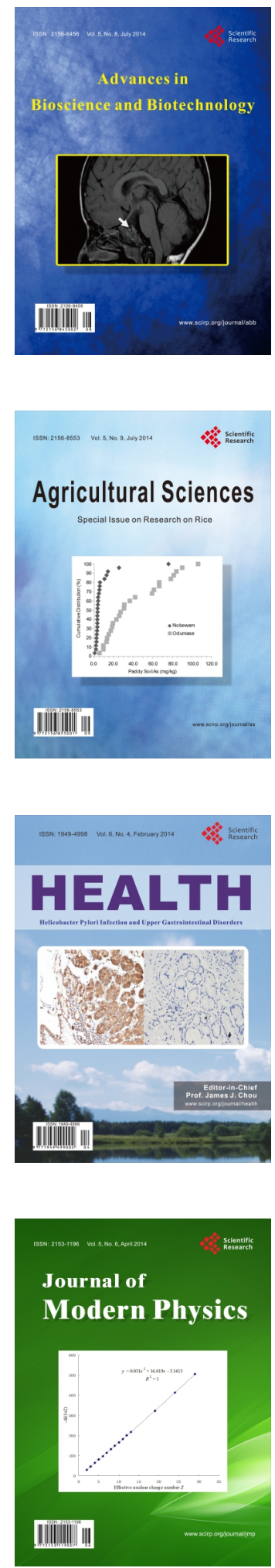
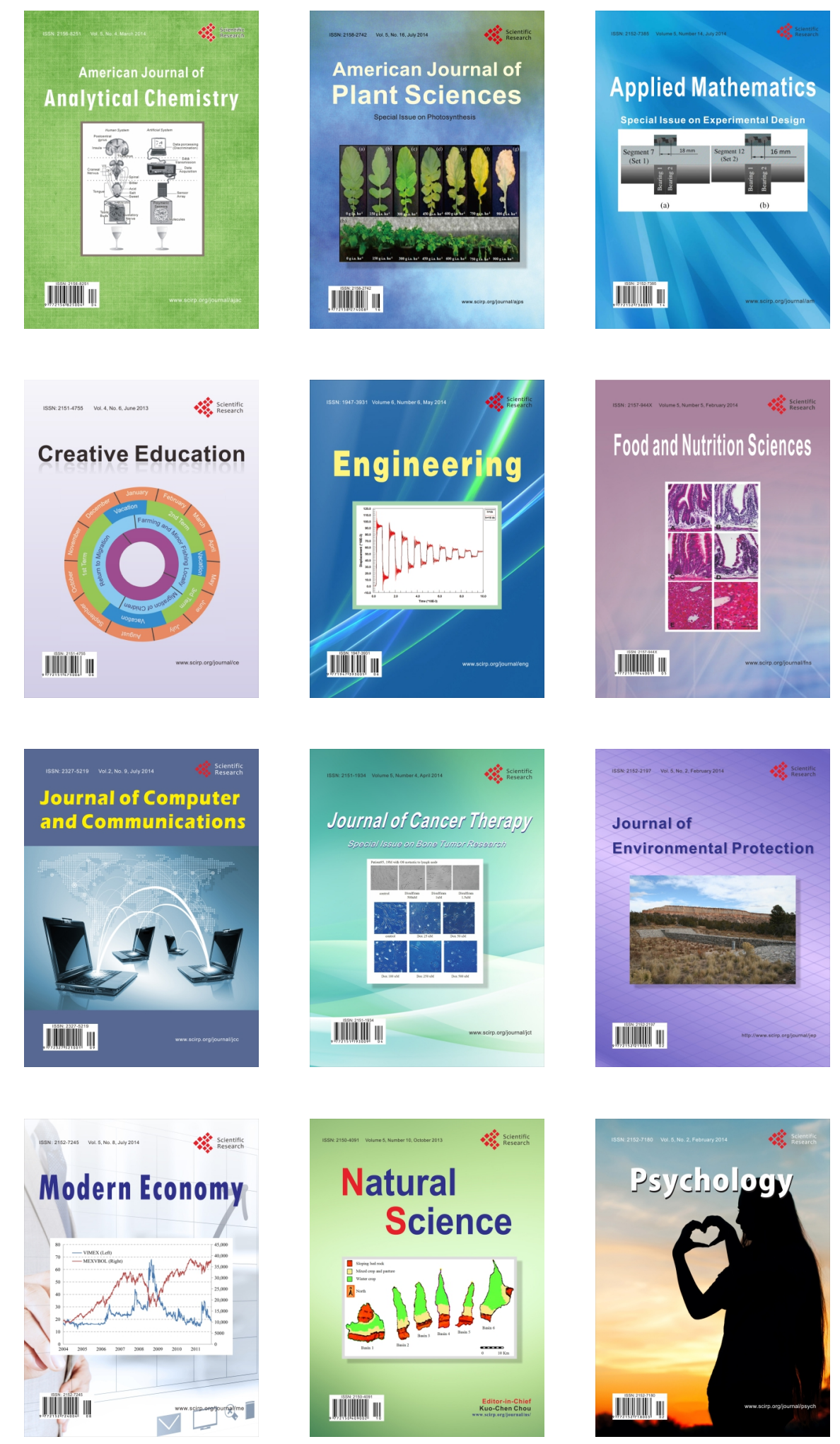